\title{
TERAPI PALIATIF DALAM PROFESI KEDOKTERAN
}

\author{
Dionisius Felenditi \\ Bagian Filsafat Fakultas Ilmu Pendidikan Universitas Negeri Manado \\ Email:dion_felenditi@yahoo.com
}

\begin{abstract}
Palliative treatment is the effort of physicians to ease the suffering of terminally ill patients. This is rather ignored because physicians give their priority to cure, prevent, promote, and rehabilitate patients based on the principle of beneficience. The palliative treatment should be paid attention to due to the sophistication of the medical profession. However, it is bypassed when faced with terminally ill patients. This palliative treatment should be intergrated with the four priorities mentioned above, which are already stated in the Indonesian Medical Code of Ethics. Nowadays, modern medical technics have been applied in the management of patients, including terminally ill patients; therefore, it is not ethical to allow a terminally ill patient to undergo suffering to the end of his/her life.
\end{abstract}

Keywords: palliative care, terminal patient, suffering.

\begin{abstract}
Abstrak: Terapi paliatif merupakan upaya para dokter untuk mengurangi penderitaan pasien terminal. Tugas ini agak terabaikan karena para dokter lebih mengutamakan tugas kuratif, preventif, promotif, dan rehabilitasi berdasarkan the principle of beneficence. Terapi paliatif ini perlu mendapat perhatian karena sehebat apapun profesi kedokteran untuk mempertahankan kehidupan pasien, namun suatu saat akan berhenti bila menghadapi pasien terminal. Tugas terapi paliatif harus terintegrasi dengan keempat tugas di atas yang memang merupakan tugas utama dalam profesi kedokteran sebagaimana tercantum dalam Kode Etik Kedokteran Indonesia. Dewasa ini, tehnik kedokteran modern sekarang menyediakan banyak kemungkinan untuk meringankan penderitaan pasien terminal, sehingga tidak etis membiarkan pasien terminal dalam menjalani akhir hidupnya dengan sangat menderita.
\end{abstract}

Kata kunci: terapi paliatif, pasien terminal, penderitaan.

Kata "paliatif" berasal dari kata Latin pallium (mantel); kata kerja palliare yang berarti mengenakan mantel pada, menutupi. Terapi paliatif seolah-olah "menutup dengan mantel", artinya menciptakan keadaan nyaman bagi pasien dan sedapat mungkin meringankan penderitaannya. Istilah ini berhubungan dengan wilayah tindakan kedokteran yang menitikberatkan pada tindakan medis untuk meringankan dan mencegah penderitaan pasien, terutama pasien yang menderita penyakit kronis dan pasien terminal yang sangat menderita dalam proses mendekati akhir hidupnya. Terapi paliatif merupakan tugas profesi kedokteran yang mulia dalam memberikan kualitas hidup yang lebih baik pada pasien, walau dalam kondisi prognosis buruk. ${ }^{1,2}$

Dalam dunia kedokteran, tidak semua dokter berani memberikan terapi paliatif, yang menimbulkan kesan seakan-akan terapi paliatif hanya merupakan kompetensi bidang tertentu. Kondisi terminal pasien yang menerima terapi paliatif membuat dokter merasa memiliki risiko tanggung gugat yang lebih besar. Tindakan meringankan penderitaan pasien ini dipandang berisiko seperti kematian, efek samping akibat dosis obat yang tinggi, dan risiko lain yang membuat dokter enggan melaksanakannya. Hal 
ini dapat dipahami mengingat tujuan utama profesi kedokteran ialah menyembuhkan, atau bila dirumuskan dengan lebih luas yaitu memromosikan kesehatan. ${ }^{2}$

Para dokter dalam menjalankan tugasnya terutama berdasar pada prinsip berbuat baik (principle of beneficence) yang memberi dokter beberapa kewajiban: 1) One ought to prevent evil or harm; 2) One ought to remove evil; dan 3) One ought to do or promote good. Prinsip ini dijadikan dasar pelayanan para dokter sampai pada upayaupaya mempertahankan kehidupan pasien terminal sedapat mungkin seolah-olah tanpa batas. Bila upaya kuratif yang maksimal tidak berhasil lagi untuk mempertahankan kehidupan pasien, maka seolah-olah tindakan medis telah berakhir. ${ }^{3}$

Dalam konteks pasien terminal yang sangat menderita, masih terdapat tugas lain bagi para dokter, yaitu terapi paliatif. Reichel mengusulkan agar pasien yang tidak mungkin ditolong lagi dan sudah mendekati ajal, perlu diberi kelonggaran untuk memperoleh obat pengurang rasa sakit, termasuk kelonggaran dalam dosisnya. ${ }^{4} \mathrm{Ke}$ wajiban untuk mendampingi pasien dan memberikan terapi yang baik (to comfort and care) tetap harus dijalankan selama pasien masih berada dalam tanggungjawabnya. Demikian pula bila pasien memilih untuk tinggal di rumah daripada di rumah sakit. Dokter harus menghindarkan diri dari penggunaan berbagai teknologi canggih dan mahal bila semua tindakan itu tidak akan menolong. Tugas ini sering diabaikan karena para dokter cenderung melakukan delegasi tugas akhir medis ini yakni "terapi paliatif" kepada para perawat sebagai pendamping pasien. ${ }^{1-4}$

\section{MANFAAT TERAPI PAIATIF}

Dewasa ini terapi kuratif menjadi sangat dominan. Dengan adanya kemajuan luar biasa dalam ilmu dan teknologi medis, peluang untuk menyembuhkan semakin meningkat. Harapan sembuh sangat berperan penting yang membuat terapi kuratif amat populer di kalangan profesi kesehatan. Callahan mengemukakan bahwa keber- hasilan medis ini mengakibatkan suatu sikap agresif dan tidak mau menyerah. Profesi kedokteran yang memakai teknologi modern sering cenderung berjuang terus untuk mengobati pasien dan seolaholah tidak mau menerima fakta bahwa pasien tidak dapat disembuhkan. Callahan menyebut sikap ilmu kedokteran ini sebagai the technological brinkmanship, yakni sikap gegabah teknologi medis untuk sampai pada ujung kehidupan. Peluang kecil 5\% untuk keberhasilan sudah menjadi alasan untuk mengusahakan kemoterapi bagi pasien kanker stadium lanjut yang akan membuatnya sangat menderita. Operasi bypass untuk pasien penyakit jantung di Amerika Serikat sekarang masih diberikan kepada pasien berusia 80-an tahun walaupun pada usia tersebut terdapat risiko besar terjadi komplikasi. ${ }^{2}$

Terapi yang bersifat paliatif menjadi hal yang bertentangan. Ketidak adanya harapan sembuh pada pasien dan peluang terjadinya risiko tanggung gugat membuat terapi paliatif kurang diminati. Inggris merupakan negara pertama yang secara khusus memperhatikan terapi paliatif, yang diakui sebagai suatu spesialisasi medis sejak 1987. Callahan juga menegaskan bahwa profesi medis tidak perlu merasa "kalah", bila pasien meninggal. Kematian harus diterima sebagai bagian dari kehidupan. Para dokter tidak perlu "mengusir" kematian, tetapi hanya berusaha agar pasien tidak meninggal sebelum waktunya (bila masih mungkin disembuhkan); dan bila pasien tidak dapat disembuhkan lagi (sudah terminal), dokter masih bertugas untuk menjaga agar cara meninggalnya berlangsung dengan baik. ${ }^{1,2}$

Tindakan medis untuk meringankan gejala-gejala yang mengganggu kehidupan pasien melibatkan profesi dokter, farmasi, perawat, petugas agama, pekerja sosial, psikolog, dan profesi kesehatan lainnya. Pendekatan multidisiplin ini memungkinkan tim terapi paliatif untuk melaksanakan tugas akhir ini yakni menanggapi kondisi fisik, emosi, spiritual, dan sosial yang diekspresikan oleh pasien yang sangat menderita saat akhir hidupnya. Tujuan terapi paliatif ialah mempertahankan kua- 
litas hidup pasien sebagai bentuk penghargaan terhadap martabat manusia, dan menyelenggarakan suatu sistem bantuan bagi pasien yang sakit dan yang mendekati ajalnya. Terapi paliatif tidak bermaksud mempercepat kematian, tetapi Engelhard berpendapat bahwa para dokter dibenarkan untuk menghentikan pengobatan bila prosedur pengobatan menyebabkan penderitaan pada pasien, tanpa memberikan harapan perbaikan.5 Pada saat terapi paliatif dimulai, semua tindakan terapeutik yang agresif, penggunaan obat, maupun tindakan medis lain dihentikan, termasuk pembedahan; kesemuanya ini dilakukan untuk meringankan penderitaan pasien. ${ }^{2}$

\section{TERAPI PALIATIF DAN PRINSIP EFEK GANDA}

Unsur terapi paliatif yang paling penting ialah penatalaksanaan nyeri (pain control), misalnya untuk pasien kanker. Menghilangkan nyeri merupakan kewajiban berat bagi dokter yang merawat pasien terminal. Pellegrino malah tidak ragu-ragu menyatakan: "Relief of pain is the least disputed and the most universal of the moral obligations of the physician. He can be excused for not being able to cure his patient, but not for failing to relieve the suffering that accompanies illness". Dokter (dan tim medis) bertindak tidak etis bila membiarkan pasien menderita lebih daripada seperlunya. Dengan kemajuan kedokteran modern maka pasien tidak perlu lagi menderita nyeri fisik berlebihan. Pemberian morfin tidak lagi mempertimbangkan masalah kecanduan, karena pasien sudah terminal. ${ }^{2}$

Penatalaksanaan nyeri pada pasien terminal sangat berbeda dengan pasien biasa. Beberapa ahli berpendapat bahwa secara etis penggunaan protokol khusus dalam terapi paliatif dibenarkan, bahkan bila menyebabkan pasien lebih cepat meninggal. Tindakan ini dapat dibenarkan berdasarkan pertimbangan prinsip efek ganda (The principle of double effect). O'Donnell mengatakan: "an action, good in itself, which has two effects, an intended and otherwise not reasonably attainable good effect, and a foreseen but merely permitted concomitant evil effect, may licitly be placed, provided there is a due proportion between the intended good and the permitted evil". 6

Dalam konteks kedokteran paliatif, yang menjadi tujuan dokter dengan tindakan ini ialah menghilangkan nyeri sebagai efek baik. Pasien berpeluang meninggal merupakan efek buruk yang memang telah diketahui sebelumnya, tetapi tidak dimaksudkan secara langsung sebagai tujuan. Pasien dengan proses keganasan yang telah bermetastasis merasakan nyeri hebat. Analgetik konvensional yang diberikan tidak dapat menghilangkan nyeri lagi sehingga diperlukan pemberian morfin dengan dosis yang makin meningkat dan makin sering. Tim medis diperhadapkan pada pemberian dosis morfin yang makin meningkat yang dapat berakibat fatal bagi pasien; di satu sisi pemberian morfin merupakan satusatunya cara yang efektif pada kasus terminal ini. ${ }^{2}$ Walau pasien sebenarnya minta hidupnya diakhiri, tim medis harus meyadari bahwa eutanasia tidak boleh dilakukan dengan meningkatkan dosis morfin lagi. Pemberian morfin bertujuan baik untuk menghilangkan nyeri (efek baik) tetapi bila pasien meninggal karenanya, hal itu bukan merupakan efek yang dimaksudkan. Pada pasien yang telah biasa menggunakan morfin, penentuan dosis letal menjadi lebih sulit. Secara keseluruhan, penanganan kasus demikian cukup sulit, dan penanganan nyeri disini termasuk terapi paliatif. Pertimbangan etisnya ialah pasien tidak boleh dibiarkan menderita selama masih ada kemungkinan medis untuk mengatasi masalah nyeri. Kenyataan bahwa pasien berpeluang meninggal lebih cepat merupakan efek buruk. ${ }^{1,2,7}$

\section{PENDAMPINGAN PASIEN TER- MINAL}

Pendampingan pasien terminal dilakukan oleh tim terpadu, termasuk tenaga yang memberikan konseling psikologis. Meninggal dunia bagi setiap manusia merupakan 
sebuah pengalaman unik. Setiap orang harus menjalani fase terakhir hidupnya itu seorang diri. Pasien terminal dalam perawatan medis seyogyanya selalu didampingi profesional kesehatan yang menghantar dia ke saat terakhir itu. Konseling ini tidak perlu diberikan oleh tenaga medis; sering lebih cocok bila diberikan oleh psikolog, rohaniwan, atau saudara pasien yang berkemampuan komunikatif. ${ }^{1}$

Pada konseling dalam pemberian terapi paliatif perlu diperhatikan faktor-faktor psikologis yang berperan dalam proses meninggal dunia. Kubler-Ross, seorang psikiater di Amerika, berjasa besar dalam mempelajari dan mendiskripsikan perkembangan psikologis pasien terminal. Setiap kematian akan berbeda seperti halnya watak setiap orang yang berbeda, tetapi dapat dideskripsikan suatu perkembangan tertentu yang meliputi lima fase kematian. Umumnya pasien, terutama orang dewasa, akan berhadapan dengan fase-fase kematian ini, yang disebut mekanisme adaptasi. ${ }^{8}$

Fase pertama ialah merasa syok dan penyangkalan (denial and isolation). Pasien terkejut dan menyangkal setelah mengetahui penyakitnya yang fatal. Kurang dari satu persen pasien-pasien yang tetap berada dalam tingkatan penyangkalan sampai kematian. dan mampu menyatakan kesadaran akan kematian dengan bahasa simbolis. Semua pasien memiliki kemampuan untuk menyampaikan kepada tim medis tiga macam komunikasi basis, yakni membutuhkan bantuan; siapa yang dapat memberikan bantuan; dan apa yang dibutuhkan. Bantuan pada saat-saat terakhir kehidupan ini juga tidak selalu diberi dalam bentuk kata-kata, tetapi bisa cukup dengan kehadiran yang tenang sambil ikut merasakan apa yang sedang dirasakan pasien; dengan demikian mampu mengomunikasikan cinta dan pelayanan baginya. Fase kedua ialah kemarahan (anger). Pasien memberontak, agresif, marah dan protes bahkan terhadap Tuhan. Dokter, perawat, dan terutama keluarga terdekat menjadi sasaran khusus kemarahannya. Pasien-pasien muda paling berat menghadapi situasi kematiannya. Tim medis harus mengerti dan menerima kemarahan pasien agar dapat menghantar pasien (dan keluarganya) ke fase berikut. Fase ketiga ialah tawar-menawar (bargaining). Pasien mencoba tawar-menawar dengan penyakit yang mengancam dirinya, dokter, atau Allah agar dengan kondisi tertentu penyakit dapat diatasi. Pasien berkonsultasi dengan dokter yang lebih ahli atau mencoba pengobatan alternatif. Selama fase ini, pasien tampak tenang dan berencana seakan-akan berada dalam kedamaian. Fase ini merupakan kesempatan terakhir bagi tim medis dan keluarga untuk membantu dia dan mengumpulkan anggota keluarga untuk mendengarkan penyampaian keinginan terakhir atau untuk menemui anak-anak yang mungkin ditinggalkannya. Fase keempat ialah berkabung (depression). Pasien menjadi sedih sekali, menutup diri terhadap dunia luar, sampai jatuh dalam depresi. Saat ini yang paling sulit untuk berkomunikasi dengan pasien. Fase kelima ialah penerimaan atau persetujuan (acceptance). Pasien telah menerima akhir hidupnya dengan rela dan pasrah. Dalam situasi ini pasien diam, tenang, dan damai walaupun sering masih merasakan penderitaannya., 2,8-11

Walaupun tidak semua pasien kanker dan pasien terminal lainnya dalam proses meninggalnya melewati lima fase kematian ini, pemahaman mengenai fase-fase ini perlu diperhatikan oleh tim medis agar dapat memberikan terapi paliatif yang memadai. Dokumen WHO (Cancer Pain Relief, Geneva, 1986) mengenai Palliative care mengemukakan: 1) affirms life and regards dying as a normal process; 2) neither hastens nor postpones death; 3) provides relief from pain and other distressing symptoms; 4) integrates the psychological and spiritual aspects of patient care; 5) offers a support system to help patients live as actively as possible until death; and 6) offers a support system to help the family cope during the patient's illness and in their own bereavement. Radiotherapy, chemotherapy and surgery have a place in palliative care, provided that the symptomatic benefits of treatment clearly outweight the disadvantages. Investigative procedures are kept to a minimum". 


\section{SIMPULAN}

Para dokter perlu memperhatikan dan melaksanakan tugas "terapi paliatif" secara terintegrasi dengan tugas kuratif, preventif, promotif dan rehabilitasi yang merupakan tugas utama dalam profesi kedokteran sebagaimana tercantum dalam Kode Etik Kedokteran Indonesia. Terapi paliatif tidak boleh diabaikan karena bagaimanapun hebatnya profesi kedokteran untuk mempertahankan kehidupan pasien, namun suatu saat akan berhenti bila berhadapan dengan pasien terminal. Bila tugas kuratif berakhir, maka terapi paliatif sangat bermanfaat pada pasien terminal yang sangat menderita. Dewasa ini kedokteran modern menyediakan berbagai kemungkinan untuk meringankan penderitaan pasien terminal, sehingga tidak etis membiarkan pasien tersebut menjalani akhir hidupnya dengan penuh penderitaan.

\section{DAFTAR PUSTAKA}

1. Duncan AS, Dunstan CR, Welbourn RB. Dictionary of Medical Ethics. London: Darton Longman \& Todd, 1981.

2. Bertens K. Etika Biomedis, Seri Filsafat
Atma Jaya: 29. Yogyakarta: Kanisius, 2011.

3. Beauchamp T, Childress J. Principles of Biomedical Ethics (Second Edition). Oxford: Oxford University Press, 1983.

4. Kartono M. Teknologi Kedokteran dan Tantangannya terhadap Bioetika. Jakarta: PT. Gramedia Pustaka Utama, 1992.

5. McCormick RA. Life and its preservation. Theological Studies. 1981;47(1):104.

6. Donnel T. The principle of the double effect. In: Orville N. Griese, editor. Catholic Identity in Health Care: Principles and Practice. Massachusetts: The Pope John Center, 1987; p. 246-54.

7. Sampurna B, Syamsu Z, Dwijasiswaja D. Pengantar Bioetika. Jakarta: Departemen Kedokteran Forensik FKUI, 2008.

8. Kubler-Ross E. Dying as a human psychological event. Concillium. 1974;4(10):48-53.

9. Greshake G. Towards a theology of dying. Concillium. 1974;4(10):96.

10. Laksmi AL, Kieser B. Kematian dan penghayatan hidup. Umat Baru. 1979;XII(67-68):77-8.

11. Mayer-Scheu J. Compassion and death. Concillium. 1974;4(10):11-9. 